\title{
DESIGN AND ANALYSIS OF AN ELECTRIC KART
}

\author{
Sathish kumar $\mathbf{N}^{1}$, Vignesh $\mathbf{A}^{2}$

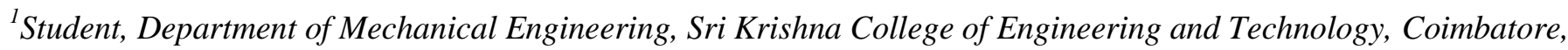 \\ Tamil Nadu, India \\ ${ }^{2}$ Student, Department of Production Engineering, Government College of Technology, Coimbatore, Tamil Nadu, India
}

\begin{abstract}
This paper presents the design and analysis of an electric motor powered kart. The main aim of this paper is to reduce the usage of organic fuel powered vehicles and to design a vehicle which works efficiently in the emerging electric vehicle sector. In order to maintain the speed levels of the kart, seamless decision was made in motor selection. Alternate materials have been applied in the kart to reduce both static and dynamic forces in pursuance of improving the efficiency and performance of the kart. Detailed design of subsystems like chassis frame, steering system, electrical power train and braking mechanism has been done effectively. The main focus of the frame design was on the stability of the kart and safety of the driver. The CAD model of the kart was done in CREO 2.0. Aluminium alloy 6063 has been employed for the frame to reduce the overall weight. To check the feasibility of the frame design, finite element analysis has been done using ANSYS 14.5. The results obtained showed that the frame design was safe under maximal impact load conditions. Weight reduction was a major concern and hence linkage type steering was selected for the kart. Motor, the heart of the electric vehicle was selected and installed in such a way that it can perform well for an extended run time. PMDC motor was selected in this case. Speed control of the kart was done using a voltage controller. The kart is provided with a timing belt drive to achieve maximum efficiency in transmission of power from the motor to the wheels. Hydraulic disc brakes were provided for smooth and effective braking under both dry and wet conditions. Slick tires are used to provide more traction. Design calculations were carried out and optimum results were obtained. An extensive market survey was also done on frame material, brakes, motor, transmission system for cost and availability. International standards were followed throughout the design process.
\end{abstract}

Keywords: Stability, Frame, Finite Element Analysis, PMDC Motor, Timing belt - ***

\section{INTRODUCTION}

The general definition of any kart, a vehicle without suspension and differential. It is a vehicle specially designed for a flat track race. A wide range of engine karts were on track since the mid of the twentieth century. [7] The present automotive scenario encourages eco-friendly vehicles to minimize the damage done by the emissions. An effective alternative for the engine is the electric motor which in comparison can give the same output power. [2] This can be implemented in the karting field. Motor replaces the engine and hence the kart gets dramatically changed in both design and performance. The vehicle, hence runs only on electricity and is designed to meet the necessary requirements for karting. The design of the frame indicates that it is an open kart with a straight chassis. The frame acts as a suspension in karts. It must also be rigid not to break under extreme load conditions. Hence, flexibility should be compromised with stiffness. The primary objective is to design a stable and safest vehicle for the driver. Every subsystem is designed based on the primary objective and then integrated into a final blueprint. 3D modelling and assembly of the whole vehicle is done in PTC CREO 2.0 and rendering is done in SOLIDWORKS 13. Finite Element Analysis is carried out on the frame model in cases of front, side and rear impact in ANSYS 14.5. Based on the result obtained from the above tests the design is modified accordingly. The center of gravity is kept as low as possible to obtain maximum stability. The length of the vehicle is shortened so as to reduce the weight of the vehicle. The wheelbase and track width of the vehicle are chosen accordingly. The front track width is minimized to reduce the turning radius of the vehicle and to increase the maneuverability. [1] The isometric views of CAD model of the vehicle is shown in fig-1 and fig- 2 .

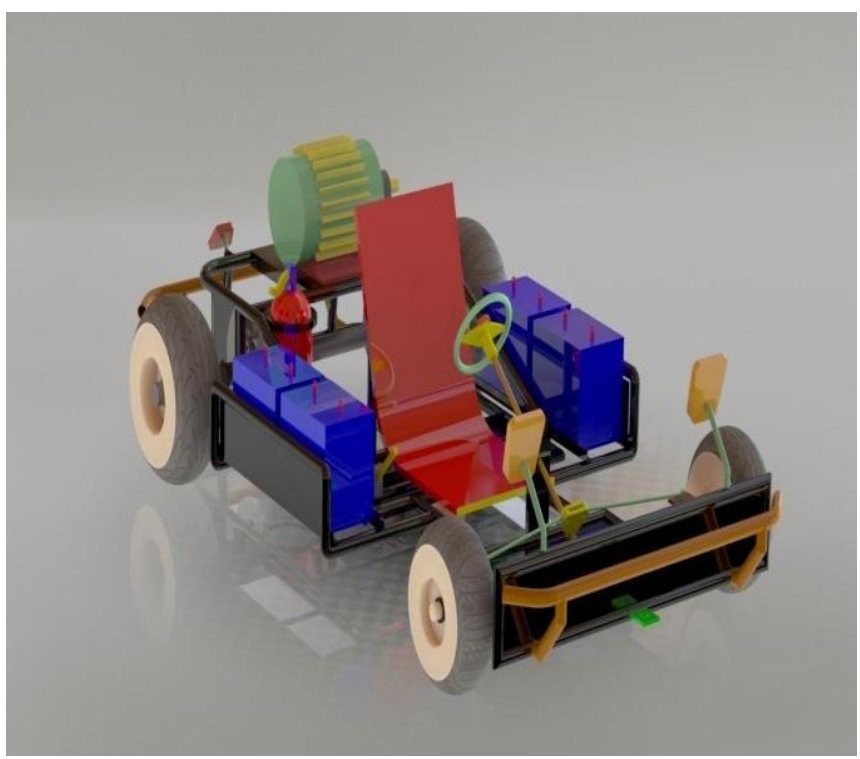

Fig -1: Isometric view of CAD model-I 


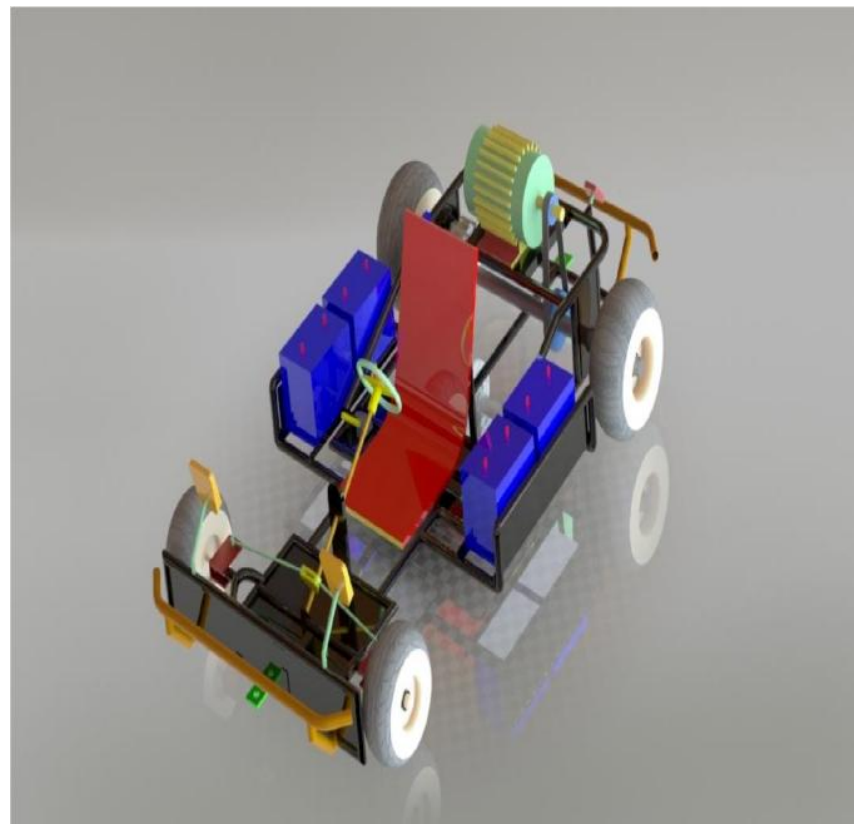

Fig -2: Isometric view of CAD model-II

\section{FRAME DESIGN}

Design of the frame consists of numerous factors like material selection, pipe size selection, safety of the driver, weight reduction, size and cost. [3] The crucial objective of the frame is to provide a safe driving environment to the driver keeping in mind the weight, space and cost. The chassis frame was designed to withstand driver weight, bump loads (the frame acts as a suspension in karts), motor weight and transmission weight. It is also required to maintain a ground clearance of 3 inches. Pedals of brake and accelerator were installed at the extreme front position to reduce the length of the vehicle. Taking into account all the necessary dimensions such as wheelbase, track width, driver dimensions and motor dimensions, the initial pencil sketches and 2D drawings for the frame were drawn. Fulfilling all the factors, the 3D model was designed. Primary analysis was done and changes were made on the frame to obtain double the strength. The isometric view of the 3D model of chassis frame of the vehicle is shown in fig-3. The material selection and cross section determination is explained below.

\subsection{Frame Material Selection}

Material selection of the frame plays a crucial part in providing desired strength, endurance, safety and reliability of the vehicle. To choose an optimal material we did an extensive study of properties of different light-weight materials. Finally, we had decided to go with aluminium alloy for the frame. The cost of different aluminium alloy pipes were reviewed. The strategy behind selecting the material for the frame was to achieve maximum welding area, good bending stiffness, minimum weight and maximum strength for the pipes. Based on the cost and availability aluminium alloy 6063 has been selected for the frame.

\subsection{Pipe Size Determination}

The pipe size determines the strength and load carrying capacity of the vehicle. Based on the availability the dimensions were selected. The outer diameter of the pipe is $25.4 \mathrm{~mm}$ and the wall thickness is $3 \mathrm{~mm}$.

To check whether the frame material's strength and the pipe dimensions selected for the vehicle's design is safe under bending, the frame is considered to be a single unit like a straight beam, free body diagram of the frame considering major weights were constructed and the maximum bending moment was found from the bending moment diagram. [3] Calculations were carried out in the frame and the results were tabulated in table-1.

Table-1: Frame design calculations

\begin{tabular}{|l|l|}
\hline Parameter & Values \\
\hline Weight of the frame & $20 \mathrm{~kg}$ \\
\hline Driver weight & $60 \mathrm{~kg}$ \\
\hline Yield strength of Al alloy 6063 & $214 \mathrm{MPA}$ \\
\hline Maximum bending moment of frame & $247.8 \mathrm{Nm}$ \\
\hline Maximum bending stress & $195 \mathrm{MPA}$ \\
\hline
\end{tabular}

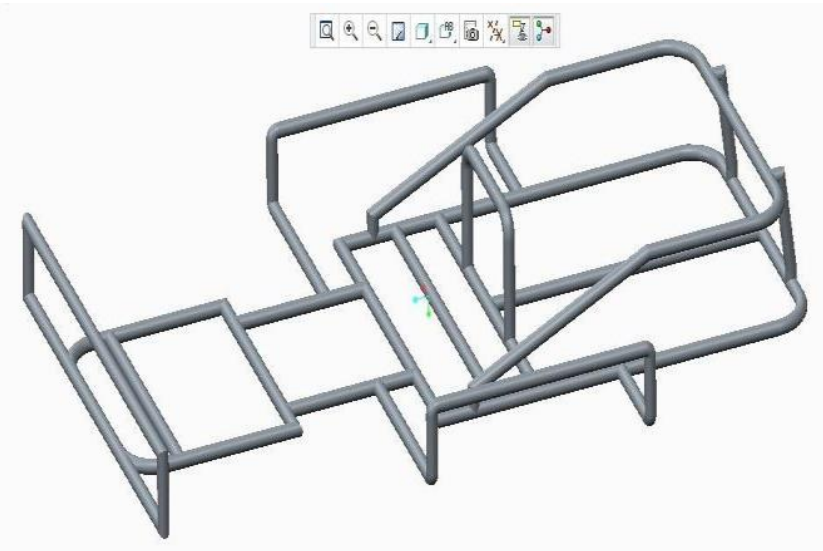

Fig -3: Isometric view of frame

Maximum bending stress is less than the yield strength of the material. Hence the frame design is safe under bending for chosen dimension and material.

\subsection{Finite Element Analysis}

To ensure that our frame is double in strength and structurally rigid to withstand the impacts while in the state of rest (or) motion, Finite Element Analysis was done on the frame. [4] Various impact tests were conducted in the frame to find the strength, reliability and safety of the kart. The frame was subjected to front impact, side impact and rear impact. The impact load for these tests were calculated from the mass-momentum equation. The impacts are purely elastic collision and the velocities for the impact tests were taken according to The European New Car Assessment Program. [5] Mesh generated in ANSYS 14.5 is shown in fig-4. The factor of safety for the impact tests is shown in fig-5, fig-6 and fig-7. 


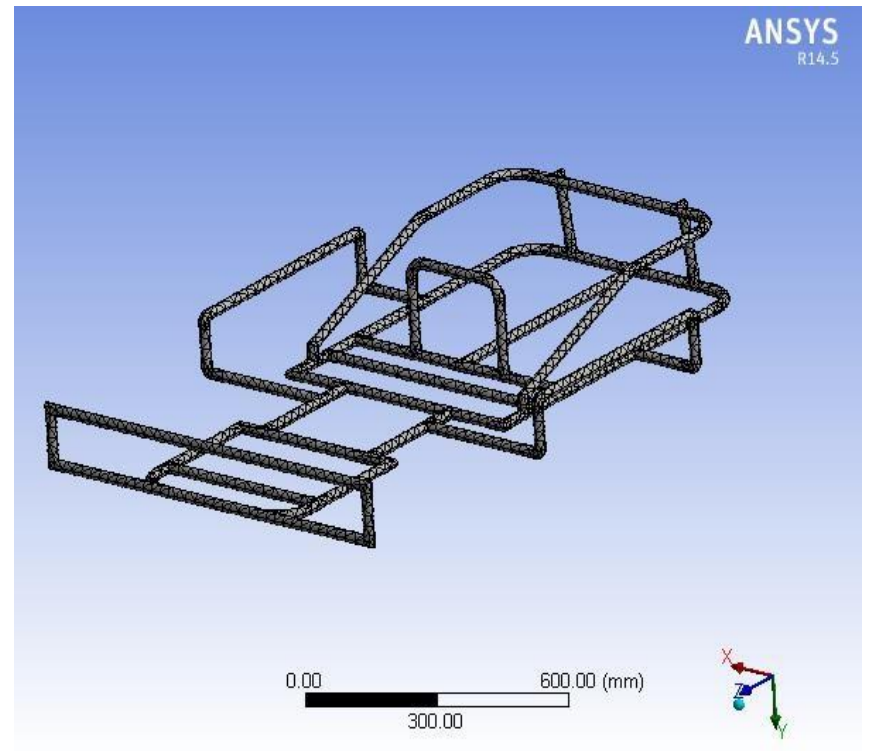

Fig -4: Mesh generated frame

The ENCAP velocity for front impact test was found to be $64 \mathrm{~km} / \mathrm{hr}$. [5] Results for the front impact test is shown in table-2. The equivalent stress was found to be within the yield stress. Hence a factor of safety of 2.07 is achieved.

Table-2: Results of front impact test

\begin{tabular}{|l|l|l|}
\hline S.no & Parameters & Result \\
\hline 1 & Load & $2667.67 \mathrm{~N}$ \\
\hline 2 & Velocity & $64 \mathrm{~km} / \mathrm{h}$ \\
\hline 3 & Equivalent stress & $103.15 \mathrm{MPA}$ \\
\hline 4 & Safety factor & 2.07 \\
\hline
\end{tabular}

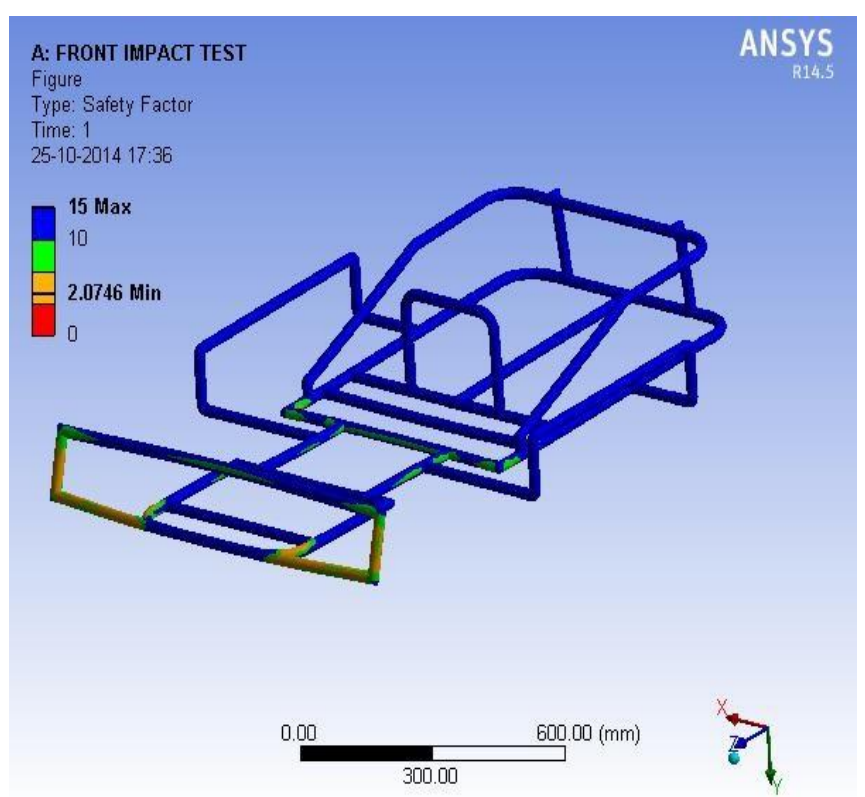

Fig -5: Front Impact test (F.O.S)

The ENCAP velocity for side impact test was found to be 50 $\mathrm{km} / \mathrm{hr}$. [5] Results for the side impact test is shown in table3. The equivalent stress was found to be within the yield stress. Hence a factor of safety of 2.20 is achieved.
Table-3: Results of side impact test

\begin{tabular}{|l|l|l|}
\hline S.no & Parameters & Results \\
\hline 1 & Load & $2083.33 \mathrm{~N}$ \\
\hline 2 & Velocity & $50 \mathrm{~km} / \mathrm{h}$ \\
\hline 3 & Equivalent stress & $96.885 \mathrm{MPA}$ \\
\hline 4 & Safety factor & 2.20 \\
\hline
\end{tabular}

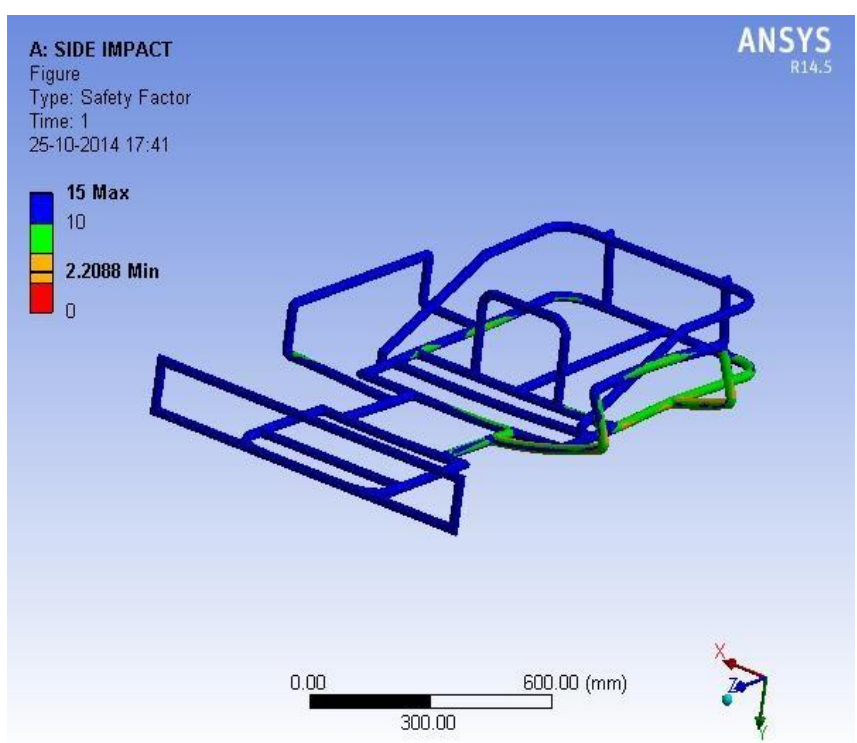

Fig -6: Side impact test (F.O.S)

The ENCAP velocity for rear impact test was found to be 64 $\mathrm{km} / \mathrm{hr}$. [5] Results for the rear impact test is shown in table4. The equivalent stress was found to be within the yield stress. Hence a factor of safety of 3.80 is achieved.

Table-4: Results of rear impact test

\begin{tabular}{|l|l|l|}
\hline S.no & Parameter & Result \\
\hline 1 & Load & $2666.67 \mathrm{~N}$ \\
\hline 2 & Velocity & $64 \mathrm{~km} / \mathrm{h}$ \\
\hline 3 & Equivalent stress & $54.99 \mathrm{MPA}$ \\
\hline 4 & Safety factor & 3.80 \\
\hline
\end{tabular}

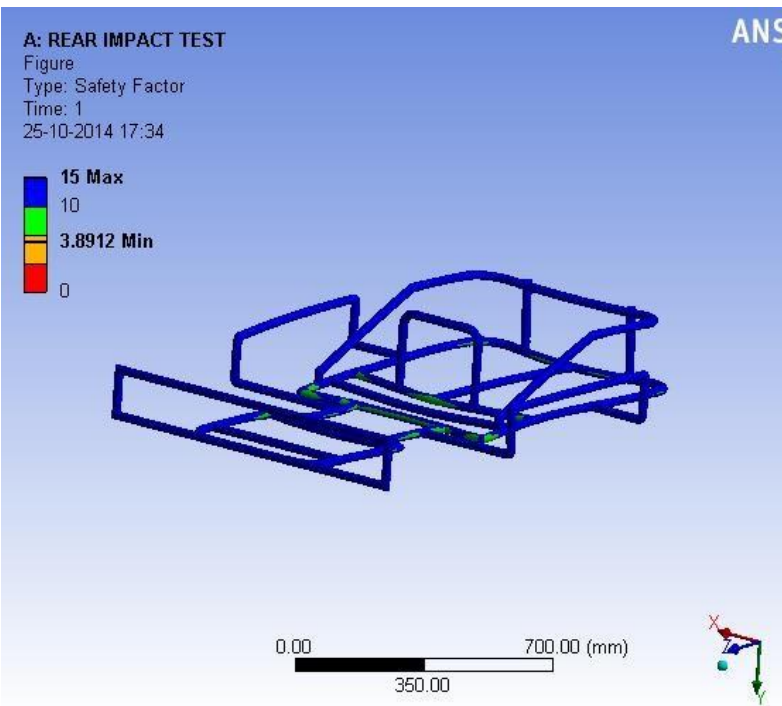

Fig -7: Rear Impact test (F.O.S) 
The above results clearly indicate that the design was safe under all impact load conditions. Hence the frame design was safe and successful.

\section{STEERING SYSTEM}

The essentials still remaining the same, the importance of steering mechanism cannot be compromised with. The stability of the steering system and response time are vital factors in deciding vehicle's run. [1] Considerations of mounting ease, compact frame and simplicity in design, made us to go with the linkage type steering. The main goal of our steering system is to provide directional control with minimum turning radius. Simplicity and safety were the main design considerations of our steering system. The steering system includes steering wheel, steering column, steering arm, tie rod and knuckle. Common inner wheel angle for any automobile is 41 degrees and outer wheel angle ranges from 28 to 29 degrees. [1] In order to achieve those angles, the stoppers were attached, intentionally on both sides of the frame such that the angular movement of steering arms is restricted to desired position. From the known inner wheel and outer wheel angles, reverse engineering process is carried out to find the turning radius of the kart by using the simple Ackermann principle. [1] The steering wheel has a led display, reverse gear toggle switch and buttons to set desired vehicle speed attached to it. Steering calculations were shown in table-4. The reduced front track provides a turning radius of $1.65 \mathrm{~m}$. The simple model of our steering system and CAD model of Steering system employed in the kart is shown in fig-8 and fig-9.

Table-4: Steering calculations

\begin{tabular}{|l|l|}
\hline Parameter & Values \\
\hline Inner wheel angle & 41 degrees \\
\hline Outer wheel angle & 28.53 degrees \\
\hline Turning Radius & $1.65 \mathrm{~m}$ \\
\hline Steering effort & $70 \mathrm{~N}$ \\
\hline Steering ratio & $1: 1$ \\
\hline
\end{tabular}

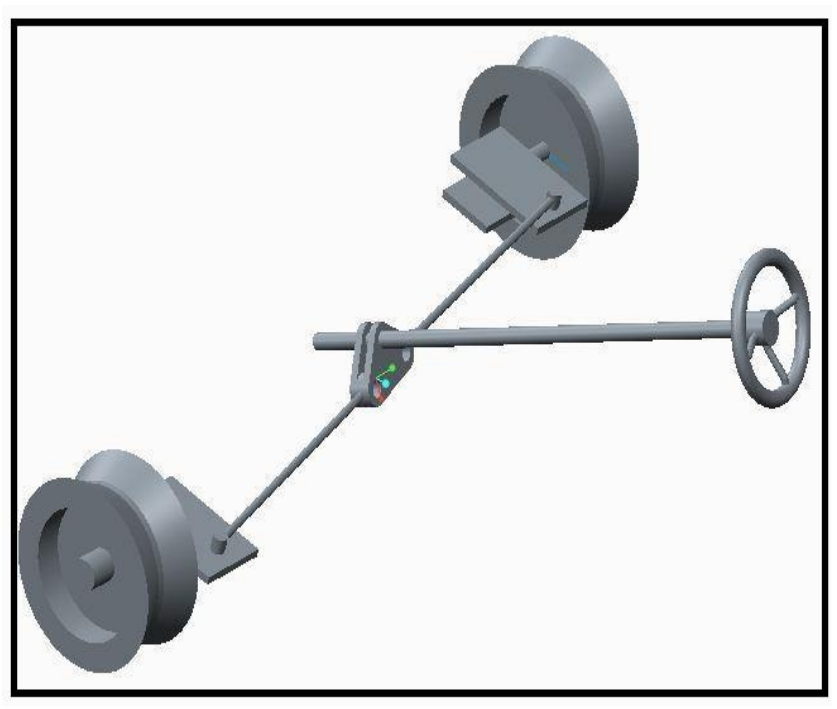

Fig -8: Steering assembly-I

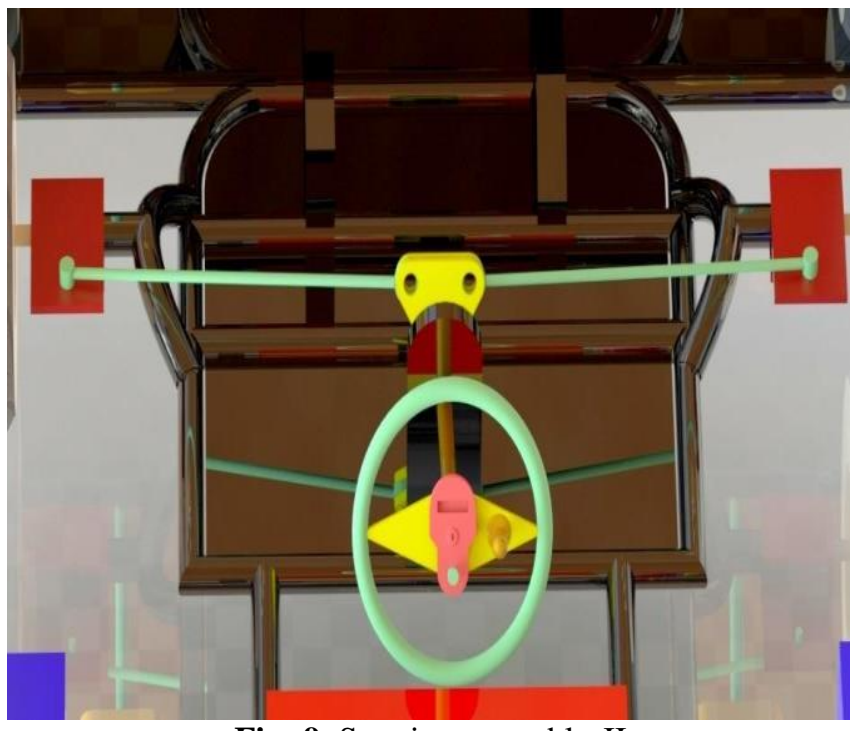

Fig -9: Steering assembly-II

\section{BRAKING SYSTEM}

An excellent braking system is the most important safety feature of any land vehicle. A karting vehicle requires an efficient braking system that provides adequate braking power to the wheels. The main requirement of the vehicle's braking system is that it must be capable of stopping all four wheels. Reliability, performance and simplicity are the main considerations in our brake design. A hydraulic brake circuit is designed in accordance with the vehicle weight, vehicle length and top speed .The disc brake assembly fits on the transmission shaft. When the brakes are applied, first the transmission shaft is being slowed down (or) partially stopped and then the wheels are simultaneously stopped. We used Apache RTR 180 disc brake assembly design in our kart. The braking system includes brake pedal, master cylinder, brake hose, caliper assembly and brake disc. Braking calculations were done at a velocity of $25 \mathrm{~km} / \mathrm{h}$ and the results were shown in table-5. Brake system layout is shown in fig- 10 .

Table-5: Braking calculations

\begin{tabular}{|l|l|}
\hline Parameter & Values \\
\hline Brake pedal force & $500 \mathrm{~N}$ \\
\hline Fluid pressure & $0.98 \mathrm{MPA}$ \\
\hline Pedal ratio & $5: 1$ \\
\hline Braking torque & $119.7 \mathrm{Nm}$ \\
\hline Braking force & $785.3 \mathrm{~N}$ \\
\hline Temperature & $180^{0} \mathrm{C}$ \\
\hline Work done by braking & $3619.9 \mathrm{~N}$ \\
\hline Stopping distance & $4.6 \mathrm{~m}$ \\
\hline Braking distance & $4.1 \mathrm{~m}$ \\
\hline Deceleration & $5.83 \mathrm{~m} / \mathrm{s}^{2}$ \\
\hline Stopping time & $1.2 \mathrm{sec}$ \\
\hline Frictional force & $1333.04 \mathrm{~N}$ \\
\hline Caliper force ( normal ) & $1110.87 \mathrm{~N}$ \\
\hline $\begin{array}{l}\text { Human perception } \\
\text { time/reaction time }\end{array}$ & $0.5 \mathrm{~s}$ \\
\hline
\end{tabular}




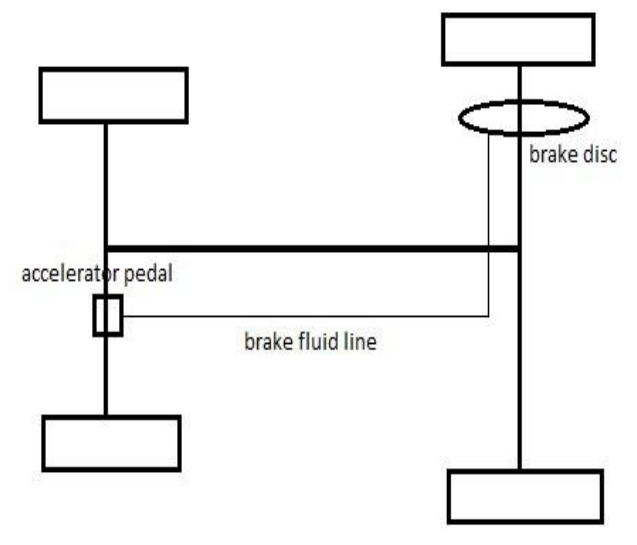

VEHICLE BRAKE SYSTEM LAYOUT

Fig -10: Brake system layout

\section{POWER TRAIN}

The main objective of the drive train is to transmit power from the motor to the wheels. The velocity, acceleration and torque of the vehicle are all concerned with the power train. An extensive research in performance, cost and availability was done, finally based on low cost and availability PMDCMotor has been chosen for our vehicle. [2] Comparison of various transmission systems had been done and finally timing belt was chosen for power transmission. [6] The motor power is transmitted to the driving shaft through the timing belt drive. The main goal of transmission design is to compromise both torque with speed to improve vehicle dynamics during acceleration, maneuvering and cornering. [1] So satisfactorily a gear ratio of $2: 1$ is chosen in accordance with our design and rule constraint. Taking into account the space available, the desired gear ratio, the output power, speed and weight of the vehicle the driven pulley and driver pulley's tooth and diameter are determined.

\subsection{Electrical Transmission}

The PMDC motor that we are implementing in our kart is a $2.5 \mathrm{~kW}$ powered $48 \mathrm{~V}$ motor. An equivalent of $48 \mathrm{~V}, 42 \mathrm{~A}-\mathrm{hr}$ lead acid battery is used to quench its thirst. The electrical circuit consists of a microcontroller, and series of resistors, capacitors and diodes and the controller have been programmed based on Pulse width modulation (PWM). The battery is connected to the motor through the PWM circuit and the main reason to use PWM method is that controlling analog circuits digitally reduce system costs and power consumption. A two-way switch attached to the steering wheel is used as a reversing key to reverse the vehicle's motion. Four secondary rechargeable 12V Sealed Lead Acid batteries in series connection are used. A 5A battery charger is fixed in the kart to charge the batteries. The battery's open circuit voltage is used in our kart to estimate the amount of charging and discharging. Keeping safety as our ultimate perspective, we have provided electrical hand brake, fuses wherever needed and two kill switches, one on the steering wheel and the other on the left side of the driver seat so that it seizes the electrical functionality of the vehicle. A display is mounted on the steering wheel that shows the driver, the vehicle's speed and the battery level. Graph showing the speed torque variations is shown in fig-11. The overall electrical layout and Simulated PWM model circuit is shown in fig-12 and fig-13.

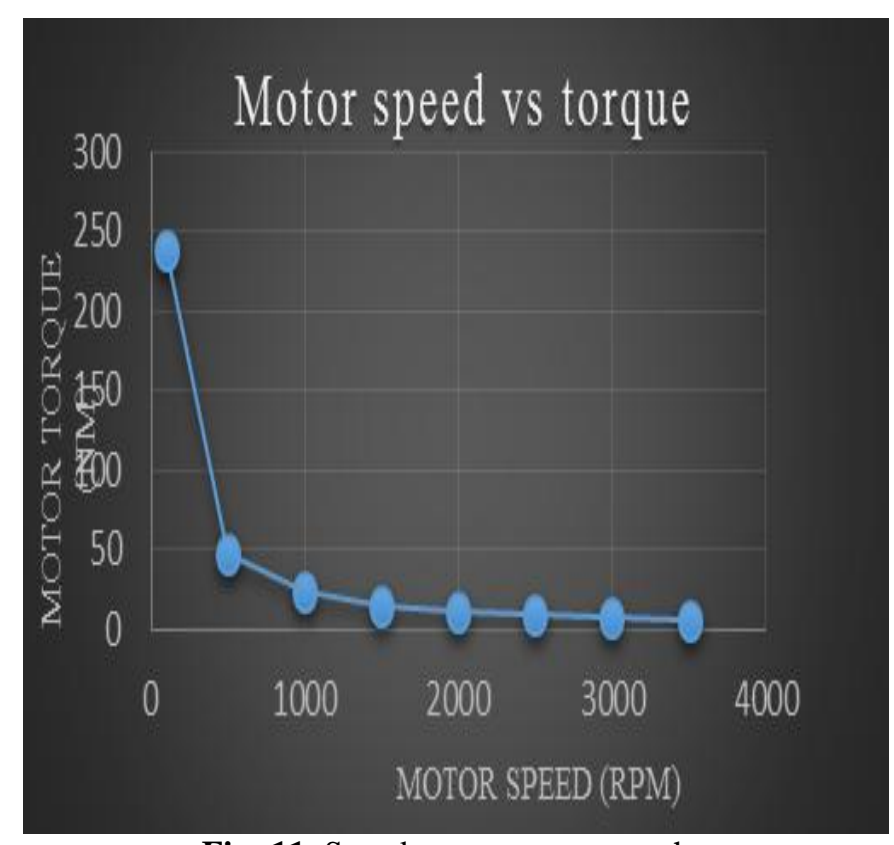

Fig -11: Speed versus torque graph

Calculations were carried out on the motor with chosen gear ratio to find the speed, design torque, velocity of the vehicle, is tabulated in table-4 and table-5. Results show that the shaft torque is greater than the motor torque and hence the vehicle will move. Hundred percent efficiency is not practically possible in any transmission system. There will be losses due to friction, heat dissipation and belt wear. Hence the motor efficiency is assumed to be 80 percent and final linear velocity of the vehicle obtained is calculated accordingly.

Table-4: Motor calculations I

\begin{tabular}{|l|l|l|l|}
\hline S.no & $\begin{array}{l}\text { Motor } \\
\text { speed }\end{array}$ & $\begin{array}{l}\text { Motor } \\
\text { torque }\end{array}$ & $\begin{array}{l}\text { Shaft } \\
\text { speed }\end{array}$ \\
\hline 1 & 100 & 238.85 & 50 \\
\hline 2 & 500 & 47.77 & 250 \\
\hline 3 & 1000 & 23.88 & 500 \\
\hline 4 & 1500 & 15.92 & 750 \\
\hline 5 & 2000 & 11.94 & 1000 \\
\hline 6 & 2500 & 9.55 & 1250 \\
\hline 7 & 3000 & 7.9617 & 1500 \\
\hline 8 & 3500 & 6.82 & 1750 \\
\hline
\end{tabular}

Table-5: Motor calculations II

\begin{tabular}{|l|l|l|l|}
\hline S.no & $\begin{array}{l}\text { Angular } \\
\text { velocity } \\
(\mathbf{r a d} / \mathbf{s})\end{array}$ & $\begin{array}{l}\text { Linear } \\
\text { velocity } \\
(\mathbf{m} / \mathbf{s})\end{array}$ & $\begin{array}{l}\text { Velocity } \\
(\mathbf{K m} / \mathbf{h})\end{array}$ \\
\hline 1 & 5.2333 & 0.7975 & 2.29 \\
\hline 2 & 26.1665 & 3.9877 & 11.48 \\
\hline 3 & 52.333 & 7.9755 & 22.97 \\
\hline
\end{tabular}




\begin{tabular}{|l|l|l|l|}
\hline 4 & 78.4995 & 11.9633 & 34.45 \\
\hline 5 & 104.666 & 15.9510 & 45.94 \\
\hline 6 & 130.8325 & 19.9388 & 57.42 \\
\hline 7 & 156.999 & 23.9266 & 68.9 \\
\hline 8 & 183.1655 & 27.9144 & 80.4 \\
\hline
\end{tabular}

To prove that the vehicle will run on selected motor specifications, transmission system and tires chosen, traction force must be greater than overall resistance. Overall resistance includes the sum of air drag, rolling and gradient resistances. Traction calculations were carried out and the results were tabulated in table- 6 .
Table-6: Traction calculations

\begin{tabular}{|l|l|}
\hline Parameter & Values \\
\hline Gear ratio & $2: 1$ \\
\hline Rolling resistance & $20.6 \mathrm{~N}$ \\
\hline Total resistance & $45.71 \mathrm{~N}$ \\
\hline Drag resistance & $10.48 \mathrm{~N}$ \\
\hline Gradient resistance & $14.71 \mathrm{~N}$ \\
\hline Traction force & $89.68 \mathrm{~N}$ \\
\hline
\end{tabular}

From the above values it is observed that the traction force is greater than the overall resistance of the vehicle and hence the vehicle moves.

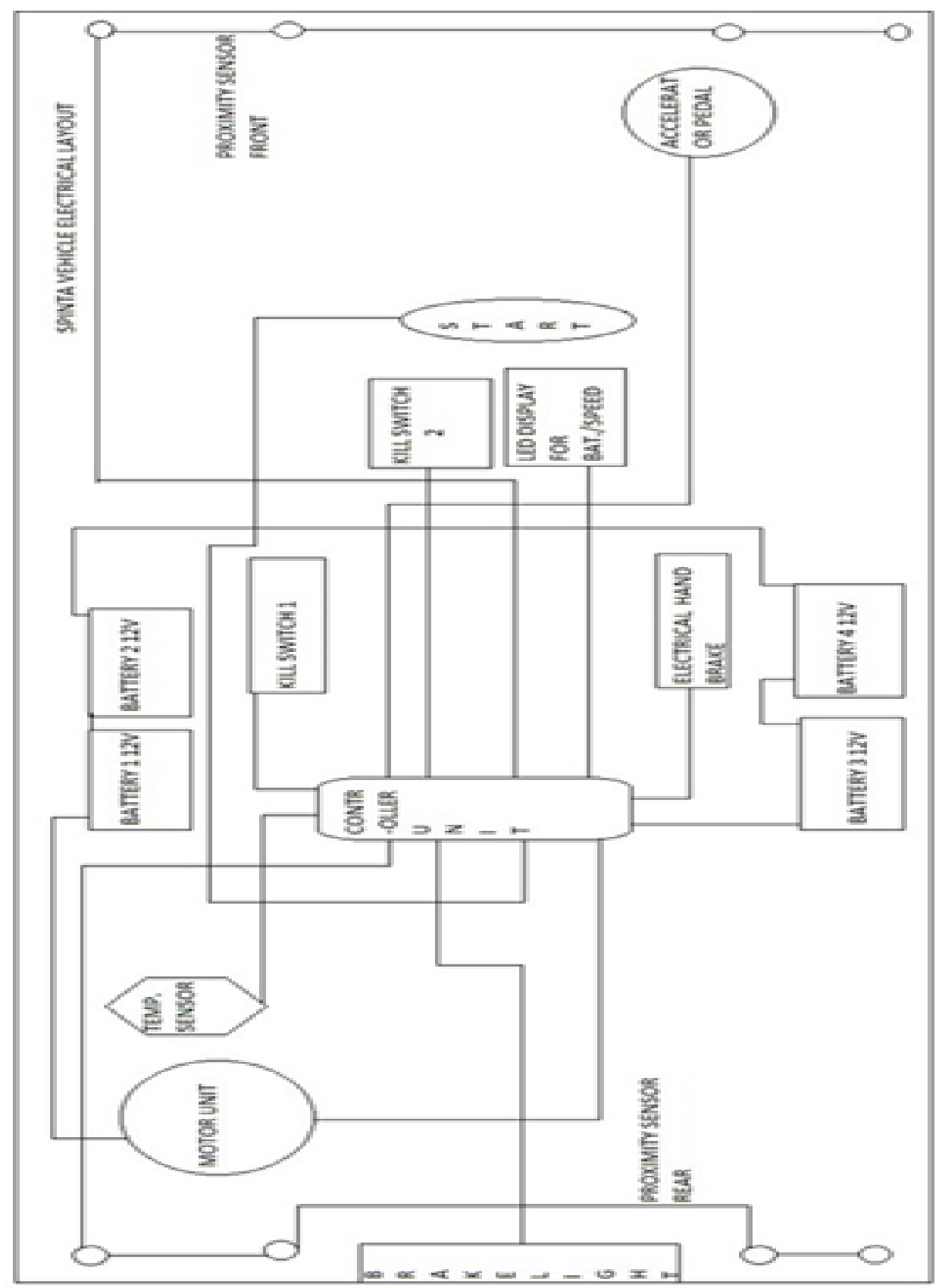

Fig -12: Vehicle electrical system layout 


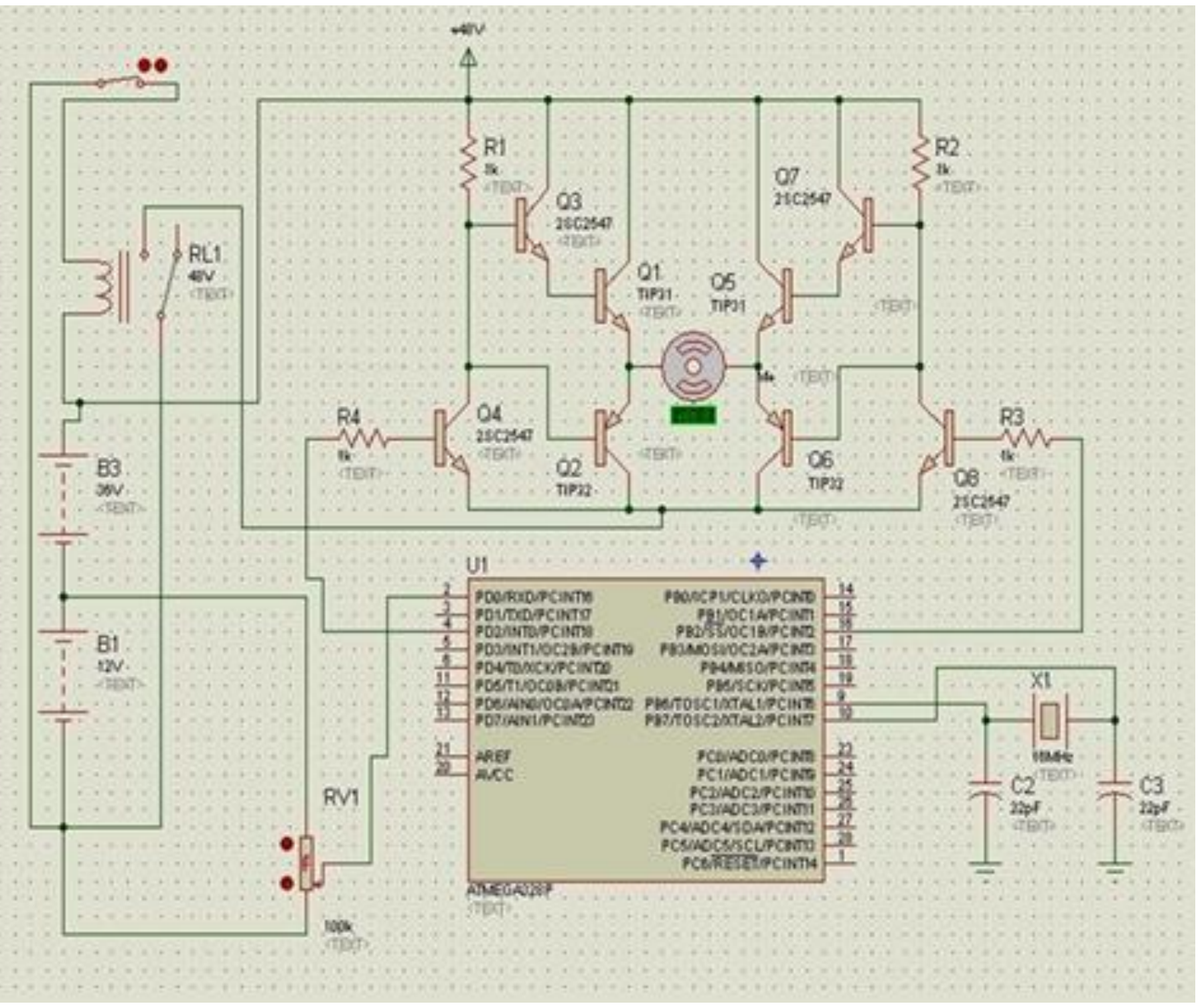

Fig -13: Simulation of electric circuit

\subsection{Mechanical Transmission}

The ultimate aim is to select an efficient and reliable drive for power transfer. Comparisons of various transmission elements have been done. Commonly used drives for power transmission are belt drive and chain drive. Primary comparison results proved that belt drive is more efficient than chain drive. Secondary analysis between the types of belts, finalized timing belt for our kart. Timing belt drives are durable, reliable and work over a wide range of speeds and torques with minimum maintenance and re-tensioning. [6] The transmission system comprises of timing belt, pulley and driving shaft and bearings. The design and selection of timing belt are based on output power. The pitch of the belt corresponding to the output power is $5 \mathrm{~mm}$. Taking the pitch as reference all other parameters involved in transmission system has been designed. The material chosen for timing belt pulley is aluminium alloy to reduce the dynamic weight and to increase the acceleration of the kart. Design stress acting on the pulley is less than the yield stress of the material. Hence the design of pulley is safe under dynamic conditions. The transmission system along with brake system is shown in fig-14. Calculation results on transmission has been tabulated in table- 7 .

Table-7: Transmission calculations

\begin{tabular}{|l|l|}
\hline Parameters & Values \\
\hline Pitch & $5 \mathrm{~mm}$ \\
\hline Pitch length & $768.86 \mathrm{~mm}$ \\
\hline Number of teeth-belt & 154 \\
\hline Total length & 768.86 \\
\hline Number of teeth-mesh & 17 \\
\hline Tight side tension & $1250.25 \mathrm{~N}$ \\
\hline Driven pulley diameter & $117.86 \mathrm{~mm}$ \\
\hline Driver pulley diameter & $58.93 \mathrm{~mm}$ \\
\hline Belt speed & $10.8 \mathrm{~m} / \mathrm{s}$ \\
\hline Effective tension of belt & $338.02 \mathrm{~N}$ \\
\hline Arc of contact & $166.15^{0}$ \\
\hline Slack side tension & $912.23 \mathrm{~N}$ \\
\hline
\end{tabular}




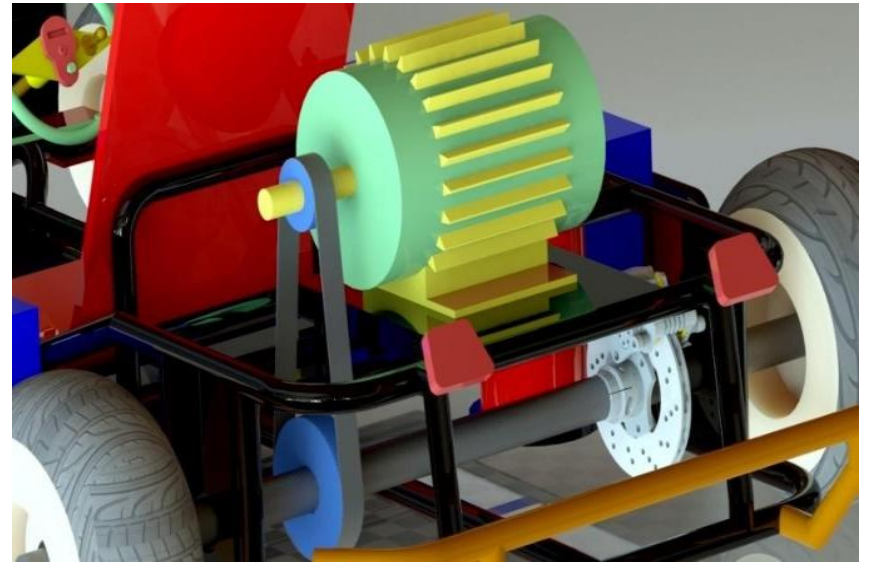

Fig -14: Transmission and brake system

\section{SAFETY, ERGONOMICS AND AESTHETICS}

Keeping safety as our primary goal, we had designed each subsystem of the vehicle. Irrespective to the design, the vehicle has many independent safety features such as 3point seat belts, fire extinguisher, kill switches, electrical hand brake, rear view mirrors, body-protection work and temperature sensor. Bumpers with impact shock absorbers is attached to the frame in front and rear ends of the vehicle to provide maximum safety to the driver during any collision. The vehicle is also designed to ergonomically take into account driver comfort and space between mounted parts. An LED display is attached to the steering wheel to indicate battery level and speed of the vehicle. Proximity sensors are attached at side ends of the vehicle to make the driver sense the danger and to prevent the vehicle from collisions. A clearance of 4" is provided between the driver seat and the side member of the frame. Considering the anthropometric data with respect to driver dimensions, the brake and accelerator pedals were placed and the driver seat is mounted at a backrest angle of $45^{\circ}$. The safety and ergonomic features included in the kart are shown in fig-15, fig-16, fig-17 and fig-18. To improve the aesthetics of the vehicle, simple body works have been done on the vehicle frame. The factors considered for selecting the bodywork material is that it should be fire resistant and water resistant. Hence our selection was an aluminium sheet for body works of our kart.

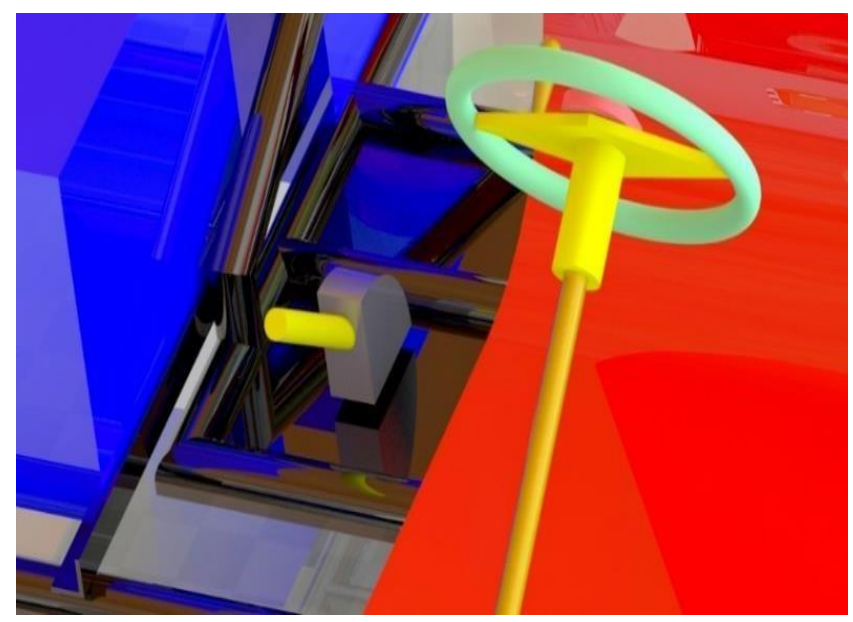

Fig -15: Electrical hand brake

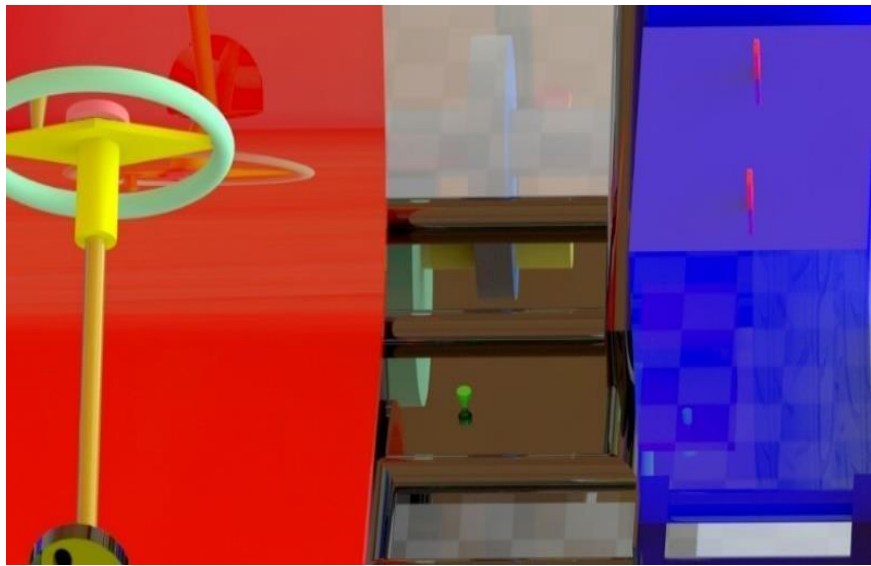

Fig -16: Kill switch

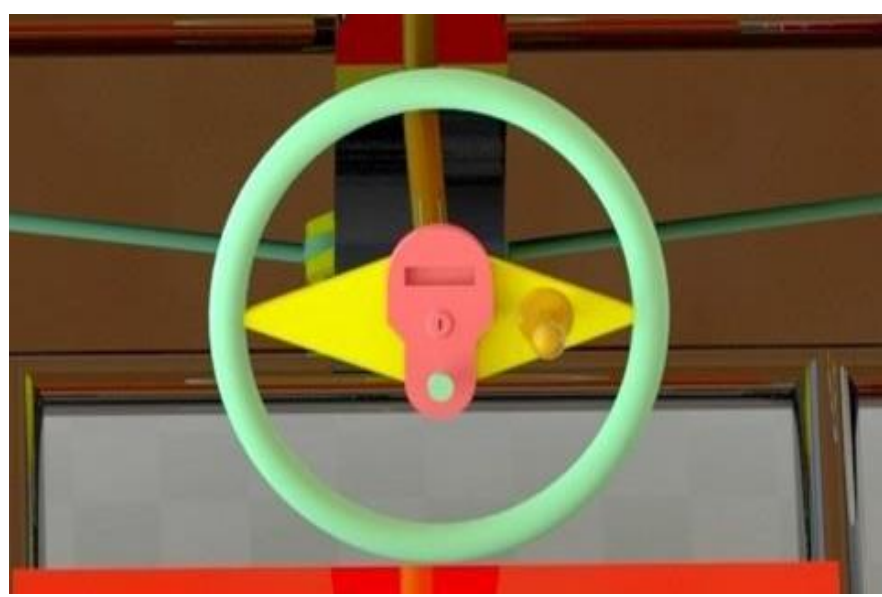

Fig -17: Reverse gear toggle switch

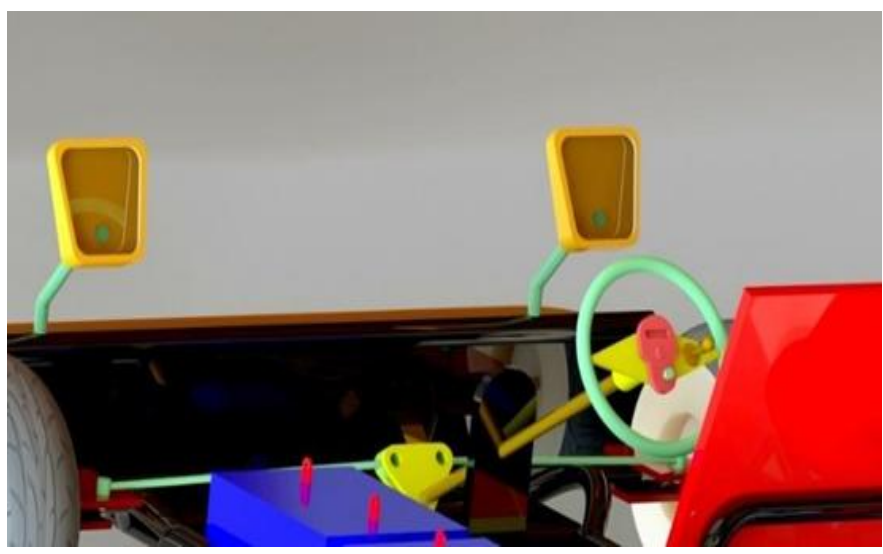

Fig -18: Rear view mirrors

\section{CONCLUSION}

Thus the kart was designed using basic automobile principles. It is analyzed using finite element techniques to prove its effectiveness. There were many challenges throughout the design process. The selection of motor to achieve the required starting torque and top speed was a challenging task. Finally a PMDC Motor of $48 \mathrm{~V}$ and $2.5 \mathrm{KW}$ was selected by conducting both theoretical and experimental studies. Hence, both speed and torque requirements are compromised and hence the speed control is achieved through a PWM based voltage controller. To make the kart more effective and efficient in performance, 
timing belt selected for power transmission is considered to be a master stroke. To come up with an excellent racing kart the subsystems were designed in such a way that they can achieve maximum performance. Finally, an effective design for the kart is developed which can outperform the existing karts and also in the upcoming era of electric automobile vehicles.

\section{REFERENCES}

[1]. "Automobile Engineering" by K K Jain, R B Asthana published 2002 by Tata McGraw-hill Publishing Company Limited.

[2]. "Electric Vehicle Technology Explained" by James Larminie and John Lowry published 2012 by John Wiley and sons limited.

[3]. Hemant B. Patil, Sharad D. Kachave, Eknath R. Deore "Stress Analysis of Automotive Chassis with Various Thicknesses" IOSR-JMCE e-ISSN: 2278-1684 Volume 6, Issue 1 (Mar. - Apr. 2013), PP 44-49.

[4]. "Practical Finite Element Analysis" by Nitin S Gokhale, Sanjay S Deshpande, Sanjeev V Bedekar, Anand N Thite published 2002 by Finite to Infinite.

[5]. http://en.wikipedia.org/wiki/Euro_NCAP.

[6]. "Design of Machine Elements" by V B Bhandari published 2010 by Tata McGraw-hill Publishing Company limited

[7]. http://en.wikipedia.org/wiki/kart_racing

\section{BIOGRAPHIES}

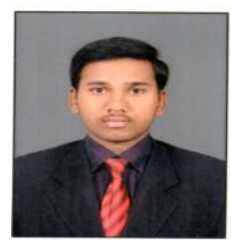

Sathish kumar $\mathbf{N}$ is a third year Mechanical engineering student. $\mathrm{He}$ is pursuing his B.E from Sri Krishna College of Engineering and Technology, Coimbatore, Tamil Nadu, India

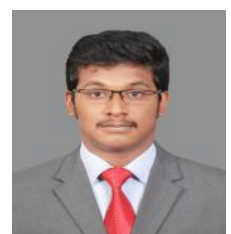

Vignesh A is a final year Production engineering student. He is pursuing his B.E from Government College of Technology, Coimbatore, Tamil Nadu, India 